Editorial

\title{
Governança das Tecnologias da Informação e ferramentas informáticas para auditoria
}

\section{Information Technology governance and informatics tools for audit}

\author{
Raul Laureano ${ }^{1}$, Álvaro Rocha ${ }^{2}$ \\ raul.laureano@iscte.pt,amrocha@dei.uc.pt \\ ${ }^{1}$ Instituto Universitário de Lisboa (ISCTE-IUL), UNIDE, Av. das Forças Armadas, 1649-026, Lisboa, \\ Portugal. \\ ${ }^{2}$ Universidade de Coimbra, Departamento de Engenharia Informática, Pólo II - Pinhal de Marrocos, 3030-
290 Coimbra, Portugal.
}

DOI: 10.17013/risti.15.vii-ix

\section{Introdução}

A governança das Tecnologias da Informação (TI) visa tornar em realidade as expectativas das organizações quando estas investem em tecnologias e sistemas de informação. De facto, as organizações desejam que as TI permitam criar valor e, assim, melhorar a sua competitividade. De outra forma, a governança visa o alinhamento dos investimentos em TI com a missão, a estratégia, os valores e a cultura das organizações e, por isso, tem vindo a ser alvo de investigação, quer por parte de académicos, quer por profissionais.

É este carácter estratégico da governança e a evidência de que processos e modelos de governança, metodologias de gestão de TI, ferramentas e métricas para avaliar os processos e as políticas de governança dependem, entre outros, do tipo de organização, da dimensão e sector de atividade, e da estrutura organizacional, que justificam o tema deste décimo quinto número regular da RISTI - Revista Ibérica de Sistemas e Tecnologias de Informação.

Este número, dedicado então à governança das TI e às ferramentas informáticas para auditoria, integra contribuições originais e relevantes nas diferentes dimensões e vertentes desta temática. Estas resultaram da submissão a este número de 29 trabalhos científicos, provenientes de oito países de dois continentes, que passaram por um processo rigoroso de avaliação. Cada artigo foi avaliado por, pelo menos, três membros do Conselho Científico, sendo mais frequente cinco membros, tendo-se selecionado para 
publicação sete artigos, correspondendo a uma taxa de aceitação de $24 \%$, valor mais elevado do que o habitual, mas que se justifica devido à qualidade dos artigos submetidos na área da governança e à, ainda, pouca aposta dos investigadores ibero-americanos pela temática das ferramentas informáticas para auditoria.

\section{Estrutura}

Para uma melhor leitura desta edição, como um todo, optou-se por apresentar as contribuições atendendo ao seu carácter: primeiro, os artigos de âmbito mais geral, e no final, os artigos de âmbito mais restrito, com foco em uma área específica da governação ou no estudo de caso de uma organização. Assim:

- No primeiro artigo, la co-creación como estrategia para abordar la gobernanza de TI en una organización, propõe-se um método baseado em cocriação para executar a fase de identificação das necessidades das partes interessadas num processo de governança. Este método ajuda a gerar debate sobre os objetivos estratégicos para as TI e pode produzir resultados inovadores no uso das TI, dependendo o sucesso, o aumento da competitividade, de uma adequada gestão do processo;

- No segundo artigo, identificação de práticas e recursos de gestão do valor das TI no COBIT 5, propõe-se, igualmente, um modelo para a identificação de um conjunto de habilitadores de Gestão do Valor das TI presentes no COBIT 5 e que resultam da integração da framework VAL IT 2.0 na framework COBIT 5. Com a adoção das práticas propostas as organizações conseguem criar valor dos investimentos realizados em TI;

- No terceiro artigo, construção de sistemas integrados de gestão para micro e pequenas empresas, reconhecendo-se as especificidades das empresas de menor dimensão e o seu elevado contributo para a economia do país, apresentase uma Macro Arquitetura para a construção de Sistema Integrado de Gestão, que inclui um conjunto de serviços integrados numa única plataforma, em regime de serviços externos (disponibilizada em regime de Software as a Service), orientado para esta tipologia de empresa e que contribua para que estas vençam os seus principais desafios;

- No quarto artigo, propuesta de marco de mejora continua de gobierno TI en entidades financieras, propõe-se um marco de melhoria continua da governação corporativa e de TI para as instituições financeiras, em que a governança de TI é parte integrante da governação corporativa. A estrutura de governo corporativo proposta garante o real alinhamento do negócio com as TI e fomenta o seguimento e uso de metodologias flexíveis;

- No quinto artigo, a governação em SI: o caso da gestão das convenções e acordos de saúde do Algarve, desenvolve-se um sistema de informação que incremente a eficiência da gestão operacional dos Meios Complementares de Diagnóstico e Terapêutica (MCDT) por parte da Administração Regional de Saúde do Algarve. Este sistema permite que os utentes e profissionais de saúde obtenham informação sobre as entidades convencionadas dos MCDT e onde as mesmas estão disponíveis no Algarve;

- No sexto artigo, Selección de salvaguardas en gestión del riesgo en sistemas 
de la información: un enfoque borroso, são analisados os problemas de seleção de salvaguardas na gestão do risco em sistemas de informação (SI) desde duas perspetivas. Na primeira, unicamente são consideradas salvaguardas que diminuem a probabilidade de transmissão de falhas na rede de ativos. $\mathrm{Na}$ segunda, dispõe-se tanto de salvaguardas preventivas como paliativas, como ainda de salvaguardas que diminuem a probabilidade de transmissão de falhas, e selecionam-se as salvaguardas que minimizam o risco do sistema sem exceder o orçamento disponível;

- Por fim, no último artigo, motivações dos auditores para o uso das Tecnologias de Informação na sua profissão: aplicação aos Revisores Oficiais de Contas, evidencia-se a importância que as TI têm como suporte à profissão de Revisor Oficial de Contas e conclui-se que as motivações dos profissionais para a utilização das ferramentas informáticas dependem do seu perfil socioprofissional e condicionam a realização de tarefas mais complexas como, por exemplo, a deteção de fraude, e consequentemente, influenciam a eficiência e eficácia do trabalho de auditor.

\section{Agradecimentos}

Apresentada a estrutura deste número, termina-se esta introdução expressando o nosso agradecimento a todos os autores que submeteram o seu trabalho científico a este décimo quinto número regular da RISTI e a todos os membros do Conselho Científico que, com rigor científico, realizarem as revisões dos artigos submetidos e cujos comentários e sugestões permitiram melhorar os setes artigos selecionados para publicação. Um agradecimento especial à AISTI, proprietária e promotora da RISTI, e à SciELO Scientific Electronic Library Online, pela sua contínua aposta e empenho em tornar a RISTI uma referência neste competitivo mercado das revistas científicas. 